\title{
Palm kernel oil increases the risk of coronary heart disease in rats compared with ghee
}

\author{
M. Khairy S. Morsi ${ }^{1}$, Samy M. Galal ${ }^{1}$, Mohamed K. Abd El-Rahman ${ }^{2}$ and \\ Mona A. Katry ${ }^{2}$ \\ ${ }^{1}$ Department of Food Science, Faculty of Agriculture, Cairo University, Egypt \\ ${ }^{2}$ National Nutrition Institute, Ministry of Health and Population, Cairo, Egypt
}

\begin{abstract}
The influence of high fat diets (HFD) containing single fat; palm oil (PO), palm kernel oil (PKO), or ghee on feed efficiency, lipid profile, kidney function and histopathological status of liver and heart of rats were studied. Male adult albino rats were fed on basal diet contained 10\% corn oil or HFD that contained either of PO, PKO, corn oil or ghee and $1 \%$ cholesterol for twelve weeks. Results showed that feeding rats on HFD containing PO or PKO significantly increased serum total cholesterol, triglycerides and VLDL-C levels compared with those of rats that were fed on basal diet or HFD containing corn oil or ghee. The highest LDLcholesterol level and the lowest total antioxidant capacity level were recorded in rats that were fed on PKO diet. The histopathological examination showed that feeding rats on HFD diet containing ghee for 12 weeks caused minimum damage to liver cells. Feeding rats on PKO diet caused undesirable histological changes in heart cells. These results indicated that $P O$ and PKO caused more harmful effects on rat's blood serum triglycerides and cholesterol concentrations and liver cells than ghee.
\end{abstract}

Keywords: Ghee, Lipid profile, Palm kernel oil, Palm oil

\section{Introduction}

PO and PKO, are undoubtedly commercially ideal raw materials for the production of various specialty fats which include cocoa butter substitute, cheese analogue, toffee fats, non-dairy fats and cream filling fats. These fats are used in products such as chocolates/coatings, toffees, coffee whiteners, ice cream, whipped toppings as cream in cake, chocolate bar, cake, candy, jelly, fried snacks such as potato chips, filler creams and non-dairy products [1]. The palm fruit (Elaeis Guineensis) is the source of both PO (extracted from palm fruit) and PKO (extracted from the fruit seeds). The PO and PKO are high in saturated fatty acids, about $50 \%$ and $80 \%$ respectively. The PO contains palmitic acid; while PKO contains mainly lauric acid [2]. Several studies on animals and human indicated that PO could increase both cholesterol levels and the atherogenic risks. Kritchevsky [3] and his colleagues studied the effects of different combinations of corn oil and PO on aspects of lipid metabolism in adult albino rats. They showed that addition of even a small amount of palmitic acid in the presence of cholesterol in diet raised serum cholesterol levels significantly. Feeding rats on diets contained 10\% coconut oil or PKO caused a significant increase in serum total cholesterol and LDL-C levels and PKO possessed a greater atherogenic risk than coconut oil [4]. Feeding hamsters on cholesterolenriched ( $1 \mathrm{~g} / \mathrm{kg}$ ) semipurified diet containing 20\% PO increased plasma total cholesterol, non-HDL-Cholesterol and decreased plasma HDL-Cholesterol significantly [5]. Feeding weaning or adult rats on $10 \% \mathrm{PO}$, PKO or palm stearin for four or six months significantly increased serum total cholesterol, LDL-C, VLDL-C, TC:HDL and LDL:HDL ratios and caused a significant decrease in HDL-C [6,7]. Fresh PO had no significant effects on blood pressure and cardiac tissue but prolonged consumption of repeatedly heated PO may result in an increase in blood pressure level with necrosis of cardiac tissue of rats [8]. Feeding rats on high PO diet caused hepatic steatosis [9]. Dietary intake of PKO could pose a risk for coronary artery disease on a long term basis [10]. It was suggested that non-extreme short-term changes in PO and dietary cholesterol consumption lead to significant elevations in plasma TC and LDL-C in humans [11]. PO and PKO should be classified as cholesterol-raising fats for humans [12]. In contrast, it was found that feeding rats or hamsters on diets that contained more than 10\% PO for 3 weeks or more improved serum and liver lipid profiles and enhanced HDLC [13-18]. They recommended that it could be useful for preventing cardiovascular disease. Dietary PO, when replacing a major part of the normal fat content in a Dutch diet, may slightly reduce the lipoprotein- and apolipoprotein-associated cardiovascular risk profiles [19]. Consumption of PO as a source of dietary fat did not pose any additional risks for coronary artery disease [2]. There are some controversies about the effect of milk fat on serum lipid and liver status in rats. In this respect, some investigators [20,21] showed a reverse association between milk fat consumption and elevation of serum lipids levels and it also developed fatty changes in liver diseases. However, some studies $[22,23]$ showed the beneficial effects of milk fat consumption on serum lipoprotein cholesterol values and it also reduces the probability of getting cardiovascular disease. 
Due to economical reasons, ghee, butter oil and butter are being replaced by PO or PKO either in cooking, bakery products and dairy products analogue. The aim of this study is to explore and evaluate, in vivo, the possible harmful effects of these oils on health, mainly cardiovascular diseases, in comparison with the butter oil, i.e. ghee.

\subsection{Oils and fats}

\section{Materials and Methods}

Refined bleached deodorized PO and PKO were obtained from Cairo Oil and Soap Company, Egypt. Corn oil (Mazola brand) was obtained from the local market. Freshly prepared Ghee (is a product obtained exclusively from milk, cream or butter by a process that almost completely removes water and nonfat solids; it has a specially developed flavor and physical structure, (codex standards [24])) was purchased from Dairy Department, Faculty of Agriculture, Cairo University, Giza, Egypt. Fatty acids composition of the investigated oils and fats were determined by using gas chromatograph (Thermo Scientific DSQ ${ }^{\text {TM }}$ II Series Single Quadrupole GC/MS, USA) equipped with a CDB-23) column (30 m, $0.25 \mathrm{~mm}$ i.d, $0.25 \mathrm{um}$ film thickness). Fatty acid methyl esters were analyzed according to A.O.A.C. [25].

\subsection{Kits for biochemical analyses}

Total cholesterol, HDL-Cholesterol and triglycerides were determined using kits purchased from Analyticon Biotechnologies AG, Germany. Albumin and total protein were determined using kits purchased from EliTech, France. Urea was determined using kit purchased from Diamond, Egypt. Creatinine was determined using kit purchased from Biomed Diagnostics, Egypt. Total antioxidant capacity was determined using kit purchased from Bio-Diagnostic, Egypt. Alanine aminotransferase (ALT) and aspartate aminotransferase (AST) were determined using kits purchased from Spectrum, Egypt. Alkaline phosphatase (ALP) was determined using kit purchased from Biosystems S.A., Spain.

\subsection{Experimental animals}

A total of 30 adult male Sprague Dawley albino rats weighing $110 \pm 10$ grams were obtained from the animal house of National Nutrition Institute, Egypt and housed in individual cages. Water and diet were given ad-libitum. The animals were kept under normal laboratory conditions and were fed on a basal diet for 7 days for adaptation. Diets were prepared biweekly and were stored in the deep freezer at $-10^{\circ} \mathrm{C}$. All animals were humanely treated in accordance with the WHO guidelines for animal care, and the study design was approved by Ethics of animal use in research committee, Cairo University with approval number (Cu F Agry/ S/ FS/ 2013/ 22).

\subsection{Experimental design}

After the adaptation period, diets and water were introduced to animals for 12 weeks. The rats were divided randomly into the following groups of six rats each: Group 1 (G1): Rats were fed on a standard Basal diet (control). Group 2 (G2): Rats were fed on a HFD containing corn oil. Group 3 (G3): Rats were fed on a HFD containing PO. Group 4 (G4): Rats were fed on a HFD containing PKO. Group 5 (G5): Rats were fed on a HFD containing ghee. The consumed diets and body weight of rats were recorded twice weekly to monitor body weight changes and calculate feed efficiency ratio. Basal diet, mineral and vitamin mixtures were prepared according to A.O.A.C. [26]. The compositions of the diets are shown in Table 1.

\subsection{Collection of blood samples and organs}

At the end of the experiment, rats were fasted for 12 hours and then they were anesthetized with diethyl ether. Blood samples were collected from the portal hepatic vein and the clear serum was separated and stored in the deep freezer at $-10^{\circ} \mathrm{C}$ for subsequent chemical analyses.

\subsection{Preparation of tissue homogenate}

Immediately after sacrificing the rats, livers and hearts were plotted free from adhering blood, washed with cold physiological saline $(0.9 \% \mathrm{w} / \mathrm{v})$, dried between filter papers and weighed. Specimens of liver were used for cholesterol determination. Liver tissue was homogenized in $10 \mathrm{ml}$ cold buffer $(50 \mathrm{mM}$ potassium phosphate buffer, pH 7.5, 1mM EDTA) per gram tissue, using tissue homogenizer. The liver homogenate was centrifuged at $4000 \mathrm{rpm}$ for $15 \mathrm{~min}$ at $4^{\circ} \mathrm{C}$. The supernatant was collected and stored at $-20^{\circ} \mathrm{C}$ for analysis.

\subsection{Nutritional assessment}

Total feed intake and body weight changes were assessed, while feed efficiency ratio was calculated for each group of rats after 12 weeks.

Feed efficiency ratio= weight gain/ Total feed intake. 
Relative weight of organs $=($ Weight of organ $/$ Rat's body weight $)$ X 100

\subsection{Biochemical analyses}

Determination of total cholesterol, HDL-Cholesterol, triglycerides, total antioxidant capacity, urea, creatinine, albumin, total protein, alanine aminotransferase (ALT), aspartate aminotransferase (AST) and alkaline phosphatase (ALP) in the serum of the investigated rats were carried out according to the kits protocols. Total lipids were extracted from liver homogenate according to Bligh and Dyer [27] and then liver cholesterol was measured according to the kit protocol. LDL-Cholesterol and VLDL-Cholesterol concentrations (mg/dl) were calculated according to the following equations of Friedwald et al [28].

LDL-Cholesterol $=[$ Total Cholesterol $]-[$ HDL-Cholesterol $]-([T G] / 5)$

VLDL-Cholesterol $=([\mathrm{TG}] / 5)$

Globulin concentration was calculated from the following equation

Globulin $=$ total protein - albumin .

\subsection{Histopathological examination}

Suitable sections of livers and hearts were fixed in $10 \%$ formalin and processed for preparation of $5 \mu \mathrm{m}$-thick paraffin sections. These sections were sequentially stained with hematoxylin and Eosin and examined for any deformation in its normal structure [29].

\subsection{Statistical analysis}

Results were reported as mean with their standard errors. The data were analyzed by one-way ANOVA; statistically significant effects were further analyzed and group's means were compared using Duncan's multiple range test. Statistical significance was determined at $(\mathrm{p}<0.05)$. Statistical analyses were done with the Costat Statistics software version 6.4 (CoHort software, California, USA).

\section{Results}

Results in Table 2 show that corn oil contains $86.4 \%$ of unsaturated fatty acids. Linoleic acid represents $66.08 \%$ of the total unsaturated fatty acids in the corn oil. The same results demonstrate that PKO, PO and ghee contain $78.4 \%, 49.9 \%$ and $64.73 \%$ saturated fatty acids, respectively. Lauric acid represents $61.2 \%$ of the total saturated fatty acids in the PKO. Palmitic acid represents $88.7 \%$ and $50.05 \%$ of the total saturated fatty acids in the $\mathrm{PO}$ and ghee, respectively.

Results in Table 3 indicate that increasing corn oil level in the diet from $10 \%$ to $20 \%$ was not accompanied by a significant increase in feed efficiency ratio in rats. Feed efficiency ratio of rats fed on diets containing 20\% PO, PKO or ghee for 12 weeks was significantly higher than that of rats fed on basal diet containing $10 \%$ corn oil. Increasing the fat level in the diet from $10 \%$ to $20 \%$ was accompanied by a significant increase in the relative weight of liver of the experimental rats regardless of the fat type used. Meanwhile, relative weight of kidney of rats fed on HFD containing corn oil or PKO was significantly lower than that of rats fed on basal diet. Results in the same Table 3 illustrate that there was no significant difference in the relative weight of kidneys of rats that were fed on HFD regardless of the fat type used. On the other hand, feeding rats on HFD for 12 weeks did not significantly affect the relative weight of the heart, spleen and testis of the experimental rats regardless of the fat source used.

Results in Table 4 show that feeding rats on HFD containing PO or PKO and 1\% cholesterol increased significantly serum triglycerides, VLDL-C and total cholesterol levels compared with those of rats that were fed on basal diet or HFD containing corn oil or ghee plus the same level of cholesterol. Results in Table 4 show that increasing the fat level in the diet to $20 \%$ was accompanied by a significant decrease in HDL-Cholesterol of the experimental rats regardless of the fat source.

Results indicate that increasing corn oil level in the diet from $10 \%$ to $20 \%$ was accompanied by a significant increase in LDL-Cholesterol of the experimental rats. LDL-Cholesterol level of rats that were fed on HFD containing ghee was significantly higher than that of rats that were fed on HFD containing corn oil. The highest LDL-Cholesterol level was recorded in rats that were fed on HFD containing PO or PKO. Feeding rats on HFD, in general, increased significantly cholesterol in their livers regardless of the fat type. Results show that increasing corn oil level in the diet from $10 \%$ to $20 \%$ was not accompanied by a significant increase in the TC/HDL ratio. Replacing corn oil by ghee in HFD did not cause a significant increase in the TC/HDL ratio. Results in the same Table 4 reveal that the highest TC/HDL and LDL/HDL ratios were recorded for the rats that were fed on HFD containing PKO. Results in the same Table 4 indicate that increasing the fat level in the diet from $10 \%$ corn oil to $20 \%$ (HFD) from corn oil, PO, PKO or ghee did not affect significantly the serum total antioxidant capacity except in the PKO group that had the lowest value.

Results in Table 5 show that increasing the fat level in the diet from $10 \%$ to $20 \%$ did not affect significantly serum albumin, globulin, total protein, A/G ratio and urea of the experimental rats regardless of the 
fat type used. Feeding rats on HFD of corn oil, PKO or ghee caused a significant increase in serum creatinine. Increasing the fat level in the diet from $10 \%$ to $20 \%$ did not affect significantly serum alanine aminotransferase (ALT) and aspartate aminotransferase (AST) of the experimental rats regardless of the fat type used.

In the histopatological examination of rat organs microscopically, normal hepatic parenchyma (Fig.1A) was noticed in the liver specimens of rats from group 1 (fed on basal diet). Meanwhile, cytoplasmic vacuolizations of hepatocytes (Fig.1B) were noticed in liver sections of rats from groups 2 and 5 (fed on HFD containing corn oil and ghee). Fatty degeneration and cytoplasmic vacuolizations of hepatocytes (Figs.1C\& 1D) were noticed in the examined sections of rats from groups 3 and 4 (fed on HFD containing PO and PKO).

No histopathological changes were noticed in the heart of rat from groups 1,2, 3 and 5 (fed on basal diet, HFD containing corn oil, PO or ghee) (Fig.2A). Meanwhile, dilatation and congestion of myocardial blood vessels (Fig.2B) were noticed in hearts of rats from group 4 (fed on HFD containing PKO).

\section{Discussion}

Present results confirmed previous results by Lai and Ney [30] that feeding rats on HFD containing PO or PKO and $1 \%$ cholesterol increased significantly serum triglycerides, VLDL-C and total cholesterol levels compared with rats fed on ghee or corn oil but contradicted with those obtained by Edem [31] who found that the total cholesterol concentration of rats that were fed on $20 \%$ corn oil diet or $20 \%$ PO diet was similar. LDLCholesterol level in rats fed on HFD containing PO or PKO was significantly higher than that of rats fed on HFD containing ghee. The LDL-Cholesterol values reflecting the harmful effect of both PO and PKO. The highest level of hepatic cholesterol was recorded in rats that were fed on HFD containing PKO followed by those fed on PO, corn oil and ghee in a descending order. Present results confirmed previous results by Bolanle and Dais [10] who concluded that dietary intake of PKO could pose a risk for coronary artery disease on a long term basis and also confirmed the Joint FAO/WHO Expert Consultation, [32] which stated that lauric (C12:0), myristic (C14:0) and palmitic acids (C16:0) consumption caused an increase in LDL-Cholesterol whereas stearic (C18:0) had no effect on LDL-Cholesterol and replacing saturated fatty acids (C12:0 - C16:0) with polyunsaturated fatty acids decreased both LDL-Cholesterol concentration and the total cholesterol/HDLcholesterol ratio. The significantly lower total antioxidant capacity level for rats fed on HFD, compared to rats fed on basal diet, was recorded in rats that were fed on HFD containing PKO which confirmed previous results in this study of the possible health risk of using this oil "PKO" as the major source of fat in the diet. Present results are in accordance with the results obtained by Edem [31] who concluded that feeding rats on 20\% PO or corn oil did not affect significantly urea and total protein. Results indicated that feeding rats on HFD from any source increased the alkaline phosphatase significantly in comparison to those fed on basal diet. This increase in alkaline phosphatase reflected the harmful effect of HFD on the liver. However, an increase in alkaline phosphatase when HFD is used for longer periods (more than 12 weeks) could be expected. Present results showed that feeding rats a diet containing $20 \%$ ghee caused minimum damage to liver cell compared with feeding rats on diets containing $20 \%$ of PO or PKO and the maximum damage in liver cells was noticed in liver cells of rats fed on HFD from PO or PKO. Feeding rats on $20 \%$ ghee caused no noticeable changes in heart tissues while dilatation and congestion of myocardial blood vessels were noticed in hearts of rats fed on a diet containing $20 \%$ PKO.

\section{Conclusion}

There are clear biochemical and histopathological evidences that PKO has harmful effects when used as a sole source of fat in a high fat diet.

\section{References}

[1] B. Hossain, Applications of palm oil and palm kernel oil in different food products of bangladish, Daffodil International University Journal of Science and Technology, 8(2), 2013, 33-38.

[2] S. Mukherjee and A. Mitra, Health effects of palm oil, Journal of Human Ecogyl, 26(3), 2009, 197-203.

[3] D. Kritchevsky, S.A. Tepper and D.M. Klurfield, Serum and liver lipids in rats fed mixtures of corn and palm oils \pm cholesterol, Nutrition Resersh, 21(1-2), 2001, 191-197.

[4] E.H. Itam, E.U. Eyong, A.E. Eno and I.J. Atangwlo, Effect of coconut (Cocus nucifera) and palm kernel (Eleasis guinensis) Oil supplmented diets on serum lipid profile of albino wistar rats. Nigerian Journal of Nutritional Sciences, 31(1), 2010, 30-34.

[5] A.H.M. Terpstra, P. van den Berg, H. Jansen, A.C. Beynen and A. van Tol, Decreasing dietary fat saturation lowers HDLcholesterol and increases hepatic HDL binding in hamsters, British Journal of Nutrition, 83(2), 2000, 151-159.

[6] C.O. Ibegbulem and P.C. Chikezie, Serum lipid profile of rats (Rattus novegicus) fed with palm oil and palm kernel oil- containing diets, Asian Journal of Biochemistry, 7(1), 2012, 46-53.

[7] M.H. Alaam, N.M.N. Yasin, S.A. Hafez and H.H.I. Mohammed, Biological and histological evaluations of palm oil and its fractions, World Journal of Dairy \& Food Sciences, 7(2), 2012, 120-130.

[8] X.F. Leong, A. Aishah, U.N. Aini, S. Das and K. Jaarin, Heated palm oil causes rise in blood pressure and cardiac changes in heart muscle in experimental rats, Archives of Medical Research, 39(6), 2008, 567-572.

[9] S. Sastri and H. Kadri, Effect of high dietary palm oil against rat hepatocytes cells. Jurnal Kesehatan Andalas 1(3), 2012, 125-128.

[10] A.O. Bolanle and A.D. Dais, Effect of oilseed diets on plasma lipid profile in albino rats, Pakistan Journal of Nutrition, 8(2), 2009, 116-118. 
[11] L.E. Bautista, O.F. Herrán and C. Serrano, Effects of palm oil and dietary cholesterol on plasma lipoproteins: results from a dietary crossover trial in free-living subjects, European Journal of Clinical Nutrition, 55(9), 2001, 748-754.

[12] M.A. Denke and S.M. Grundy, Comparison of effects of lauric acid and palmitic acid on plasma lipids and lipoproteins, American Journal of Clinical Nutrition, 56(5), 1992, 895-8.

[13] S. Lindsey, J. Benattar, A. Pronczuk and K.C. Hayes, Dietary palmitic acid (16:0) enhances high density lipoprotein cholesterol and low density lipoprotein receptor mRNA abundance in hamsters, Proceedings of the Society for Experimental Biology and Medicine, 195(2), 1990, 261-269.

[14] T.A. Wilson, R.J. Nicolosi and T. Kotyla, K. Sundram and D. Kritchevsky, Different palm oil preparations reduce plasma cholesterol concentrations and aortic cholesterol accumulation compared to coconut oil in hypercholesterolemic hamsters, Journal of Nutritional Biochemistry, 16(10), 2005, 633-640.

[15] M. Karaji-Bani, F. Montazeri and M. Hashemi, Effect of palm oil on serum lipid profiles in rats. Pakistan Journal of Nutrition, 5(3), 2006, 234-236.

[16] G.O. Eidangbe, G.C.Ojieh, B.O. Idonije and O.M. Oluba, Palm oil and egusi melon oil lower serum and liver lipid profile and improve antioxidant activity in rats fed a high fat diet. Journal of Food Technology, 8(4), 2010, 154-158.

[17] V.P. Tee, T.K. Tiu, C.H. Ming and K. Nesaretnam, Palm oil diets do not raise total/ HDL- cholesterol compared to partially hydrogenated vegetable oil diet in rats, Journal of Oil Palm Research, 24(12), 2012, 1562-1565

[18] S.A. Ali, F. Asghar, M. Nafees and M. Tayyab, Effect of nigella sativa (Kalonji) on serum lipid profile, ANNALS, 18(2), 2012, 224228.

[19] K. Sundram, G. Hornstra and A.C.V. Houwelingen, Replacement of dietary fat with palm oil: effect on human serum lipids, lipoproteins and apolipoproteins, British Journal of Nutrition, 68, 1992, 671-692.

[20] S. Akter, M.A. Miah, M.A.H.N.A. Khan and M.K. Islam, Comparative effects of animal and vegetable fats on lipid profile and patho-physiological changes in mice, Journal of Scientific Research, 5(2), 2013, 353-361.

[21] I.N. Soelaiman, Z. Merican, J. Mohamed and K. Abdul Kadir, Serum lipids, lipid peroxidation and glutathione peroxidase activity in rats on long-term feeding with coconut oil or butterfat (ghee), Asia Pacific Journal of Clinical Nutrition, 5(4), 1996, 244-248.

[22] A.M. Reddy, V. Satish, M. Nagamounica and M. Manojkumar, Myths and facts about consumption of ghee in relation to heart proplems-a comparative research study. International Journal of Pharmacy and Pharmaceutical Sciences, 5(2), 2013, 560-563.

[23] F. Asadi, A. Shahriari and M. Chahardah-Cheric, Effect of long-term optional ingestion of canola oil, grape seed oil, corn oil and yogurt butter on serum, muscle and liver cholesterol status in rats. Food and Chemical Toxicology, 48(8-9), 2010, 2454-2457.

[24] CODEX STAN A-2, Codex standard of milkfat products, Adopted in 1973, Revision 1999, Amendment 2006, 2010.

[25] A.O.A.C, Official methods of analysis of association of official analytical chemists, Official Method 963.22. Methyl Esters of Fatty Acids in Oils and Fats. Gas Chromatographic Method, A.O.A.C, Arlington, Virginia, USA, First Action 1963, Final Action 1984

[26] A.O.A.C, Official methods of analysis of association of official analytical chemists, Official Method 982.30, A.O.A.C, Washington, DC, USA, 2000.

[27] E.G. Bligh and W.J. Dyer, A rapid method of total lipid extraction and purification, Canadian Journal of Biochemistry and Physiology, 37(8), 1959, 911-917.

[28] W.T. Friedewald, R.I. Levi and D.S. Fredrickson, Estimation of the concentration of low density lipoproteins cholesterol in plasma without use of the ultracentrifuge, Clinical. Chemistry, 18(6), 1972, 499-502.

[29] D. Bancroft, A. Steves and R. Tuner, Theory and practice of histological techniques (Churchiil living stones, Edinburgh, London, Melbourne, 1996)

[30] H.C. Lai and D.M. Ney, Corn oil, palm oil and butterfat fractions affect postprandial lipemia and lipoprotein lipase in meal-fed rats. Journal of Nutrition, 125(6), 1995, 1536-1545.

[31] D.O. Edem, Hematological and histological alterations induced in rats by palm oil- containing diets. European Journal of Science Research, 32(3), 2009, 405-418.

World Health Organization, Interim Summary of Conclusions and Dietary Recommendations on Total Fat\& Fatty Acids, Joint FAO/WHO Expert Consultation on Fats and Fatty Acids in Human Nutrition,. Geneva, WHO, 10-14 November, 2008.

Table1. Composition of basal and high fat diets

\begin{tabular}{lcc}
\hline Ingredients & $\begin{array}{c}\text { Basal diet } \\
\mathrm{g} / \text { 100g diet }\end{array}$ & $\begin{array}{c}\text { High fat diet } \\
\mathrm{g} / \text { 100g diet }\end{array}$ \\
\hline Casein (85\% Protein) & 14 & 14 \\
Corn oil & 10 & 3 \\
Experimental fat (One of the following: & - & 17 \\
Corn oil-PO-PKO-Ghee) & 5 & 5 \\
Salt mixture & 1 & 1 \\
Vitamin mixture $^{\dagger}$ & 17 & 0.2 \\
Choline chloride & 0.2 & 1 \\
Cholesterol & - & 2 \\
Cellulose & 2 & 28.4 \\
Sucrose & 33.4 & 28.4 \\
Corn starch & 33.4 & \\
\hline
\end{tabular}

PO, palm oil; PKO, palm kernel oil.

* Basal diet was prepared according to AOAC (2000) [27].

$\dagger$ Vitamin and Salt mixtures were prepared according to AOAC (2000) [27]. 
Table 2. Fatty acids composition of the investigated oils and fats

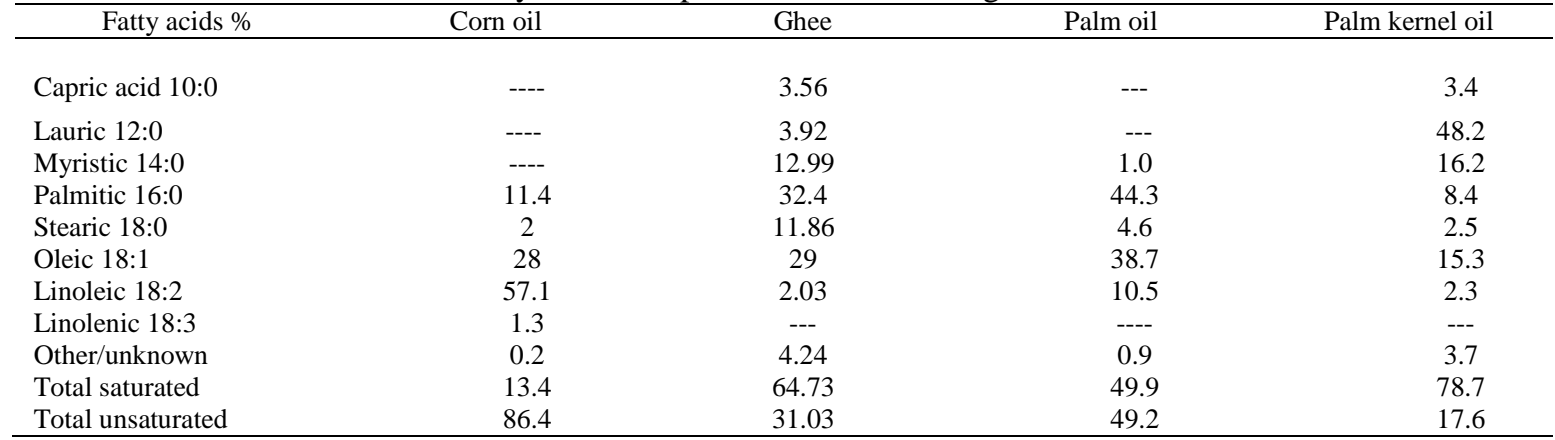

Table 3. Feed efficiency ratio (FER), relative weight (g/100g body wt) of liver, heart, kidney, spleen and testis of rats fed on basal diet or high fat diets for 12 weeks

\begin{tabular}{|c|c|c|c|c|c|c|c|c|c|c|c|}
\hline \multirow[b]{3}{*}{ parameter } & \multirow{2}{*}{\multicolumn{3}{|c|}{$\begin{array}{c}\text { Basal diet } \\
\text { Corn oil } \\
\text { (10\% fat) }\end{array}$}} & \multicolumn{8}{|c|}{ High fat diet (20\% total fat) } \\
\hline & & & & \multicolumn{2}{|c|}{ Corn oil } & \multicolumn{2}{|c|}{ Palm oil } & \multicolumn{2}{|c|}{ Palm kernel oil } & \multicolumn{2}{|c|}{ Ghee } \\
\hline & $n$ & Mean & SEM & Mean & SEM & Mean & SEM & Mean & SEM & Mean & SEM \\
\hline \multirow[t]{2}{*}{ FER } & 6 & $0.12^{\mathrm{c}}$ & 0.01 & $0.140^{\mathrm{bc}}$ & 0.008 & $0.150^{\mathrm{ab}}$ & 0.01 & $0.159^{\mathrm{ab}}$ & 0.009 & $0.175^{\mathrm{a}}$ & 0.004 \\
\hline & \multicolumn{9}{|c|}{ Relative weights of organs (g/100g body wt) } & & \\
\hline Liver & 6 & $2.37^{\mathrm{b}}$ & 0.08 & $3.37^{\mathrm{a}}$ & 0.11 & $3.19^{\mathrm{a}}$ & 0.14 & $3.18^{\mathrm{a}}$ & 0.07 & $3.37^{\mathrm{a}}$ & 0.08 \\
\hline Heart & 6 & $0.269^{\mathrm{a}}$ & 0.04 & $0.239^{\mathrm{a}}$ & 0.003 & $0.239^{\mathrm{a}}$ & 0.005 & $0.252^{\mathrm{a}}$ & 0.006 & $0.284^{\mathrm{a}}$ & 0.06 \\
\hline Kidney & 6 & $0.532^{\mathrm{a}}$ & 0.01 & $0.454^{\mathrm{b}}$ & 0.03 & $0.48^{\mathrm{ab}}$ & 0.02 & $0.461^{\mathrm{b}}$ & 0.007 & $0.471^{\mathrm{ab}}$ & 0.01 \\
\hline Spleen & 6 & $0.349^{\mathrm{a}}$ & 0.06 & $0.246^{\mathrm{a}}$ & 0.02 & $0.342^{\mathrm{a}}$ & 0.01 & $0.321^{\mathrm{a}}$ & 0.01 & $0.286^{\mathrm{a}}$ & 0.02 \\
\hline Testis & 6 & $0.810^{\mathrm{a}}$ & 0.09 & $0.825^{\mathrm{a}}$ & 0.07 & $0.854^{\mathrm{a}}$ & 0.04 & $0.805^{\mathrm{a}}$ & 0.03 & $0.723^{\mathrm{a}}$ & 0.04 \\
\hline
\end{tabular}

*The results are represented as the mean values and their standard errors. Mean values within row with unlike superscript letters were significantly different $(\mathrm{P}<0 \cdot 05$, one-way ANOVA with Duncan's multiple range test).

Table 4. Serum lipid prophile, liver cholesterol and total antioxidant capacity of rats fed on basal diet or HFD for 12 weeks

\begin{tabular}{|c|c|c|c|c|c|c|c|c|c|c|c|}
\hline \multirow{3}{*}{ Parameter } & \multirow{2}{*}{\multicolumn{3}{|c|}{$\begin{array}{l}\frac{\text { Basal diet }}{\text { Corn oil }} \\
\text { (10\% fat) }\end{array}$}} & \multicolumn{8}{|c|}{ High fat diet (20\% total fat) } \\
\hline & & & & & & & oil & Palm k & oil & & lee \\
\hline & $\mathrm{n}$ & Mean & SEM & Mean & SEM & Mean & SEM & Mean & SEM & Mean & SEM \\
\hline Triglycerides (mg/dl) & 6 & $62.0^{b}$ & 1.87 & $61.1^{b}$ & 4.16 & $128.8^{\mathrm{a}}$ & 18.6 & $119.5^{\mathrm{a}}$ & 2.53 & $75.3^{b}$ & 2.93 \\
\hline Total cholesterol (mg/dl) & 6 & $94.1^{\mathrm{b}}$ & 3.22 & $112.2^{\mathrm{b}}$ & 6.08 & $173^{\mathrm{a}}$ & 11.7 & $177.6^{\mathrm{a}}$ & 9.55 & $117.4^{\mathrm{b}}$ & 5.3 \\
\hline HDL-C (mg/dl) & 5 & $59.7^{\mathrm{a}}$ & 7.28 & $46.9^{\mathrm{b}}$ & 1.16 & $42.1^{\mathrm{b}}$ & 3.75 & $33.0^{\mathrm{b}}$ & 4.24 & $34.7^{\mathrm{b}}$ & 4.87 \\
\hline LDL-C (mg/dl) & 5 & $15.7^{\mathrm{d}}$ & 1.78 & $42.8^{\mathrm{c}}$ & 2.10 & $105.8^{\mathrm{a}}$ & 7.02 & $104.3^{\mathrm{a}}$ & 3.84 & $58.4^{\mathrm{b}}$ & 1.25 \\
\hline VLDL-C (mg/dl) & 6 & $12.5^{\mathrm{b}}$ & 0.40 & $12.2^{\mathrm{b}}$ & 0.81 & $25.7^{\mathrm{a}}$ & 3.71 & $23.9^{\mathrm{a}}$ & 0.48 & $15.0^{\mathrm{b}}$ & 0.57 \\
\hline Cholesterol in liver & 6 & $7.39^{\mathrm{e}}$ & 0.50 & $12.68^{\mathrm{c}}$ & 0.28 & $15.19^{\mathrm{b}}$ & 0.37 & $16.52^{\mathrm{a}}$ & 0.50 & $11.29^{\mathrm{d}}$ & 0.53 \\
\hline TC/HDL ratio & 5 & $1.678^{\mathrm{d}}$ & 0.26 & $2.058^{\mathrm{cd}}$ & 0.11 & $3.008^{\mathrm{b}}$ & 0.16 & $3.942^{\mathrm{a}}$ & 0.31 & $2.58^{\mathrm{bc}}$ & 0.28 \\
\hline LDL/HDL ratio & 5 & $0.516^{\mathrm{b}}$ & 0.19 & $0.818^{\mathrm{b}}$ & 0.09 & $2.061^{\mathrm{ab}}$ & 0.44 & $3.346^{\mathrm{a}}$ & 1.23 & $1.38^{\mathrm{b}}$ & 0.30 \\
\hline $\begin{array}{l}\text { Total antioxidant capacity } \\
(\mathrm{mM} / \mathrm{L})\end{array}$ & 6 & $2.24^{\mathrm{a}}$ & 0.05 & $1.92^{\mathrm{ab}}$ & 0.13 & $1.95^{\mathrm{ab}}$ & 0.11 & $1.67^{\mathrm{b}}$ & 0.19 & $1.88^{\mathrm{ab}}$ & 0.15 \\
\hline
\end{tabular}

*The results are represented as the mean values and their standard errors. Mean values within row with unlike superscript letters were significantly different $(\mathrm{p}<0 \cdot 05$, one-way ANOVA with Duncan's multiple range test). 
Palm kernel oil increases the risk of coronary heart disease in rats compared with ghee

Table 5. Serum kidney and liver functions of rats fed on basal diet or HFD for 12 weeks

\begin{tabular}{|c|c|c|c|c|c|c|c|c|c|c|c|}
\hline \multirow{3}{*}{ Parameter } & & \multirow{2}{*}{\multicolumn{2}{|c|}{$\frac{\text { Basal diet }}{\text { Corn oil }}$}} & \multicolumn{8}{|c|}{ High fat diet (20\% total fat) } \\
\hline & $n$ & & & \multicolumn{2}{|c|}{ Corn oil } & \multicolumn{2}{|c|}{ Palm oil } & \multicolumn{2}{|c|}{ Palm kernel oil } & \multicolumn{2}{|c|}{ Ghee } \\
\hline & & Mean & SEM & Mean & SEM & Mean & SEM & Mean & SEM & Mean & SEM \\
\hline Albumin (g/dl) & 6 & $3.6^{\mathrm{a}}$ & 0.12 & $3.4^{\mathrm{a}}$ & 0.08 & $3.4^{\mathrm{a}}$ & 0.24 & $3.1^{\mathrm{a}}$ & 0.16 & $3.0^{\mathrm{a}}$ & 0.20 \\
\hline Globulin (g/dl) & 6 & $2.8^{\mathrm{a}}$ & 0.32 & $2.0^{\mathrm{a}}$ & 0.44 & $2.4^{\mathrm{a}}$ & 0.24 & $2.6^{\mathrm{a}}$ & 0.53 & $3.3^{\mathrm{a}}$ & 0.53 \\
\hline Total protein $(\mathrm{g} / \mathrm{dl})$ & 6 & $6.4^{\mathrm{a}}$ & 0.44 & $5.4^{\mathrm{a}}$ & 0.40 & $5.8^{\mathrm{a}}$ & 0.16 & $5.7^{\mathrm{a}}$ & 0.40 & $6.3^{\mathrm{a}}$ & 0.48 \\
\hline $\mathrm{A} / \mathrm{G}$ ratio & 6 & $1.41^{\mathrm{a}}$ & 0.15 & $2.25^{\mathrm{a}}$ & 0.30 & $1.66^{\mathrm{a}}$ & 0.27 & $1.37^{\mathrm{a}}$ & 0.44 & $1.22^{\mathrm{a}}$ & 0.18 \\
\hline Creatinine (mg/dl) & 6 & $0.46^{\mathrm{b}}$ & 0.02 & $0.60^{\mathrm{a}}$ & 0.04 & $0.53^{\mathrm{ab}}$ & 0.01 & $0.58^{\mathrm{a}}$ & 0.02 & $0.61^{\mathrm{a}}$ & 0.036 \\
\hline Urea $(\mathrm{mg} / \mathrm{dl})$ & 6 & $31.10^{\mathrm{a}}$ & 3.02 & $29.40^{\mathrm{a}}$ & 1.95 & $29.10^{\mathrm{a}}$ & 2.89 & $31.65^{\mathrm{a}}$ & 2.24 & $32.60^{\mathrm{a}}$ & 1.26 \\
\hline $\operatorname{AST}(\mathrm{U} / \mathrm{L})^{*}$ & 5 & $70.0^{\mathrm{a}}$ & 8.94 & $50.66^{\mathrm{a}}$ & 1.86 & $60.33^{\mathrm{a}}$ & 4.05 & $67.0^{\mathrm{a}}$ & 3.13 & $58.6^{\mathrm{a}}$ & 4.49 \\
\hline $\operatorname{ALT}(\mathrm{U} / \mathrm{L})^{*}$ & 5 & $39.4^{\mathrm{a}}$ & 5.18 & $30.4^{\mathrm{ab}}$ & 3.38 & $31.8^{\mathrm{ab}}$ & 3.91 & $25.74^{\mathrm{b}}$ & 4.06 & $21.8^{\mathrm{b}}$ & 2.07 \\
\hline $\operatorname{ALP}(\mathrm{U} / \mathrm{L})^{*}$ & 6 & $80.8^{\mathrm{b}}$ & 10.81 & $116.8^{\mathrm{ab}}$ & 7.87 & $133.6^{\mathrm{a}}$ & 18.20 & $144.6^{\mathrm{a}}$ & 9.43 & $117.6^{\mathrm{ab}}$ & 5.55 \\
\hline
\end{tabular}

AST, aspartate aminotransferase; ALT, alanine aminotransferase; ALP, alkaline phosphatase.

* The results are represented as the means and their standard errors. Mean values within row with unlike superscript letters were significantly different ( $\mathrm{P}=0 \cdot 05$, one-way ANOVA with Duncan's multiple range test).
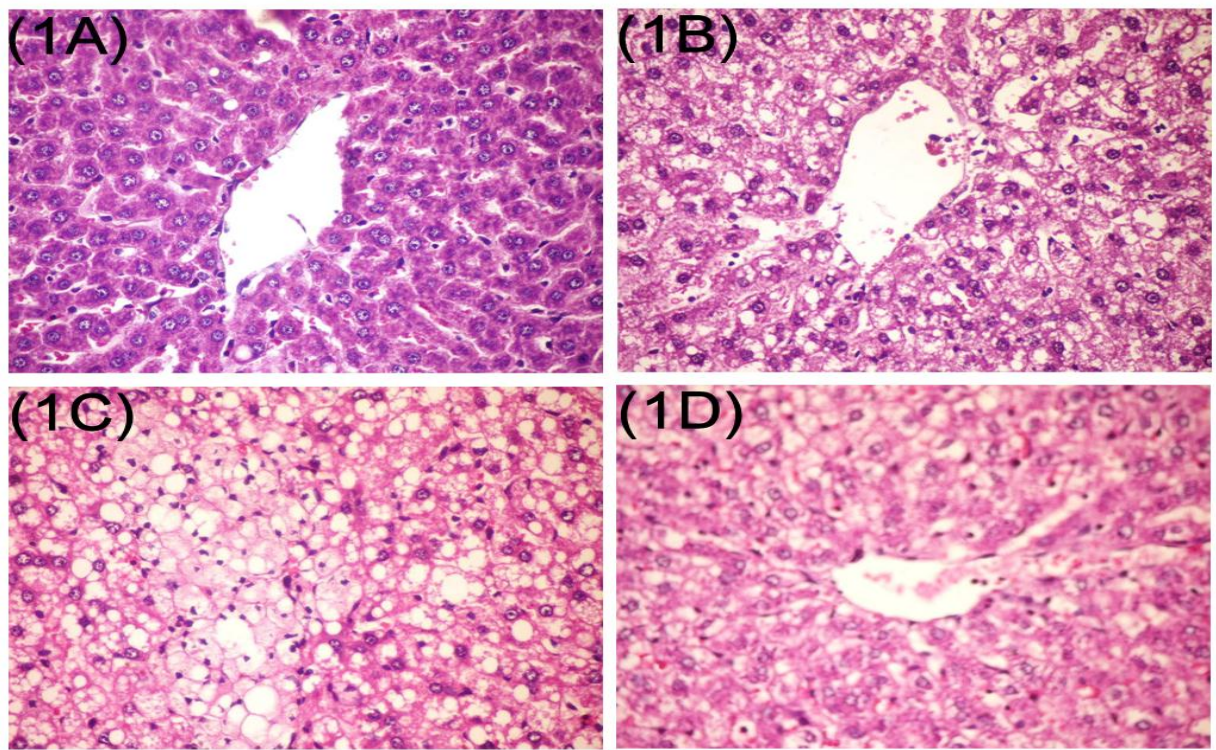

Fig1: photomicrograph of liver cells (hematoxylin and eosin $\times 400$ ). 1a, liver show normal hepatic parenchyma and no histological changes; $1 \mathrm{~b}$, liver show cytoplasmic vacuolization of hepatocytes noticed in rat groups fed on high fat diet containing corn oil or ghee; $1 \mathrm{c} \& 1 \mathrm{~d}$, liver show cytoplasmic vacuolization and fatty degeneration of hepatocytes noticed in rat groups fed on high fat diet containing palm oil or palm kernel oil.
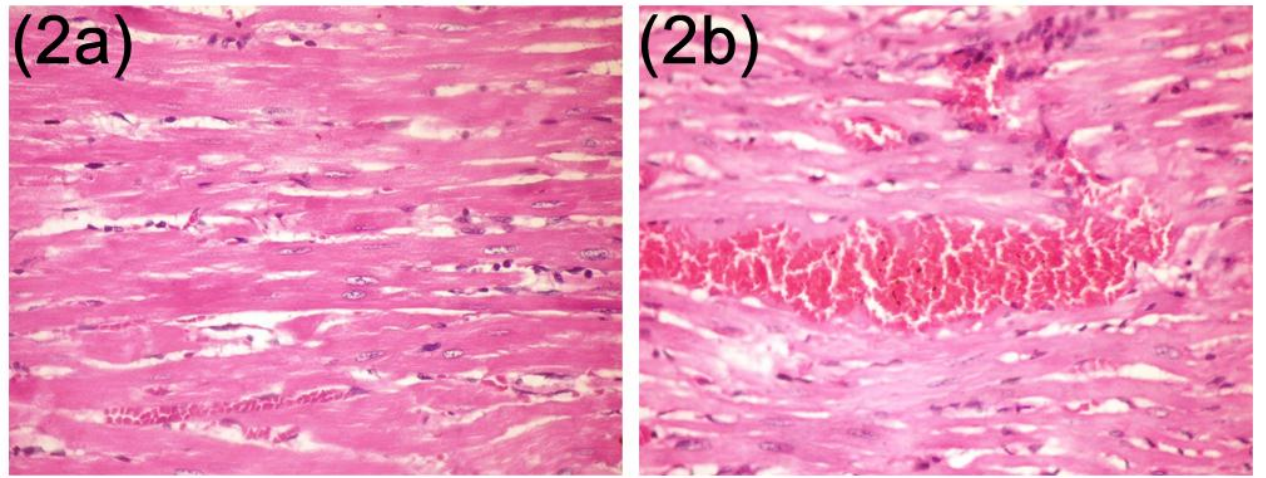

Fig2: photomicrograph of heart cells (hematoxylin and eosin $\times 400$ ). 2a, heart show no evidence of histopathological changes; $2 b$, heart show dilatation and congestion of myocardial blood vessels noticed in rat group fed on high fat diet containing palm kernel oil. 